\title{
Noise Level at Different Workplaces of Selected Oil Industries
}

\author{
Jayshree Rodge* and Bhagyashree Sangale \\ Department of Resource Management and Consumer Science, College of Community Science, \\ VNMKV, Parbhani, Maharashtra, India \\ *Corresponding author
}

Ke y w o r d s
Work place, Noise
level, Inside noise,
outside noise,
industry

The study was conducted in thirty renowned oil industries located in the selected cities of Marathawada region in Maharashtra state (Parbhani, Hingoli, Aurangabad, Jalna and Nanded) to know the inside and outside intensity level of noise. These oil industries were involved in expelling oil from cotton seeds for the last 10-12 years. All the selected oil industries were established by small and medium entrepreneurs. Measurement of noise level was made with a handy sound level meter (model no. 2013, serial no. F 04000) manufactured in India by CYGENT system. The instrument has been calibrated to give noise level from 50 $\mathrm{dB}$ to $115 \mathrm{~dB}$. Noise level inside the oil industry was noted down around the four directions of the work place and average of these readings was considered as a noise level of that workplace. Total four readings of sound level were noted at a time of 4 hrs. interval (From 9 AM. to 9 PM.). Assessment of noise pollution was determined by comparing actual level with acceptable limit of recommended noise level. The results of the study found that noise level in work place-2 (Seeds crushing) was higher than other two workplaces -1 (Seed feeding) and 3 (Oil expelling). All the three workplaces judged as very noisy while pollution percent is also high. Statistically there was highly significant relation between noise levels at all the three workplaces of oil industries and average noise level. With respect to inside and outside noise level it was noticed that average inside noise level of oil industries at 9.00 AM was $82.01 \mathrm{~dB}$, while noise level at 1.00 PM and 5.00 PM was equal i.e. $83.84 \mathrm{~dB}$ and at $9.00 \mathrm{PM} 75.49 \mathrm{~dB}$. With respect to outside noise level at 9.00 AM was 76.88 dB whereas at 1.00 PM, 5.00 PM and 9.00 PM noise levels recorded were $80.15 \mathrm{~dB}, 78.68 \mathrm{~dB}$ and $70.08 \mathrm{~dB}$ respectively. Computed ' $Z$ ' values showed highly significant difference between inside and outside noise levels at different time intervals which indicated that inside noise level was significantly higher than outside noise of selected oil industries at different time intervals of the day. An average percent pollution in inside noise levels of the oil industries as against the recommended limits was higher in Parbhani city and of outside noise level it was higher in the oil industries at Aurangabad city. 


\section{Introduction}

Each and every component in the environment has its own limit but when it increases beyond the limit that time pollution may occur.

When the word: environment pollution is mentioned, the thoughts it triggers in the minds of most of the people are usually those of water and air pollution. But nobody realizes that there is another type of insidious pollution known as noise pollution (Tiwari, 1990).

Noise pollution is a type of energy pollution in which distracting, irritating, or damaging sounds increasing urbanization and industrialization creates a lot of problems on environment as well as on our health. Noise pollution plays an important role to effects environment health.

Noise is unpleasant and undesirable sound at unwanted place. Noise levels are measured in Decibels $(\mathrm{dB})$, One decibel is the threshold of hearing. Approximately $60 \mathrm{~dB}$ is the level of normal talking.

Industrial machinery and processes are composed of various noise sources such as rotors, stators, gears, fans, vibrating panels, turbulent fluid flow, impact processes, electrical machines, internal combustion engines etc.

The mechanisms of noise generation depend on the particularly noisy operations and equipment including crushing, riveting, blasting (quarries and mines), shake-out (foundries), punch presses, drop forges, drilling, lathes, pneumatic equipment (e.g. jack hammers, chipping hammers, etc.), tumbling barrels, plasma jets, cutting torches, sandblasting, electric furnaces, boiler making, machine tools for forming, dividing and metal cutting, such as punching, pressing and shearing, lathes, milling machines and grinders, as well as textile machines, beverage filling machines and print machines, pumps and compressors, drive units, hand-guided machines, self-propelled working machines, in-plant conveying systems and transport vehicles. On top of this there are the information technology devices which are being encountered more and more in all areas (Gongi et al., 2016).

The effects of noise on human body are serious. The culmination of bad effects is that expectancy of life is decreasing day by day.

Hence the present study was undertaken to study the noise intensity level in selected industries of selected cities of Marathawada region with following objectives.

To analyze the noise level at different workplaces of selected oil industries

To study the intensity of noise level in selected industries.

\section{Materials and Methods}

The study was conducted in thirty renowned oil industries located in the selected cities of Marathawada region in Maharashtra state (Parbhani, Hingoli, Aurangabad, Jalna and Nanded) to know the intensity of noise.

These oil industries were involved in expelling oil from cotton seed for the last 10-12 years. All the selected oil industries were established by small and medium entrepreneurs.

\section{Measurement techniques used in the study}

Measurement of noise level was made with a handy sound level meter (model no. 2013, serial no. F 04000) manufactured in India by CYGENT system, which was operated with a battery. The instrument has been calibrated to give noise level from $50 \mathrm{~dB}$ to $115 \mathrm{~dB}$. 


\section{Noise level inside the oil industry}

Noise level inside the oil industry was noted down around the four directions of the work place and average of these readings was considered as a noise level of that workplace. Total four readings of sound level were noted at a time of 4 hrs. interval (From 9 AM. to 9 PM.) and average of these four readings was considered as a noise level of that work place and that day. Care was taken to avoid the influence of unwanted sound signals on the result e.g. noise due to wind on the microphone of the measuring instrument.

\section{Acceptable noise exposure limits}

Assessment of noise pollution was determined by comparing actual level with acceptable limit of noise recommended by Central Pollution Control Board (2001).

Following are the acceptable noise exposure limits.

To assess the percentage increase in noise pollution following formula was used

Percentage increase in noise pollution

$$
\text { ANL - ANEL }
$$

= --- X 100

ANL

ANL - Average Noise Level

ANEL - Average Noise Exposure Limit

Table.1

\begin{tabular}{|c|c|c|}
\hline Category of area / zone & \multicolumn{2}{|c|}{ Limits in $\mathbf{~ d B ( A ) ~} \mathbf{L}_{\mathbf{c q}}$} \\
\hline & Day time & Night time \\
\hline Industrial area & 75 & 70 \\
\hline Commercial area & 65 & 55 \\
\hline Residential area & 55 & 45 \\
\hline Silence Zone & 50 & 40 \\
\hline
\end{tabular}

Table.2

\begin{tabular}{|c|c|}
\hline Noise level (dB) & $\begin{array}{c}\text { General subjective judgment } \\
\text { (Perceived noise) }\end{array}$ \\
\hline Below 30 & Very quite \\
\hline $\mathbf{3 0}-\mathbf{4 0}$ & Quite \\
\hline $\mathbf{4 0}-\mathbf{5 0}$ & Fairly quite \\
\hline $\mathbf{5 0}-\mathbf{6 0}$ & Boarder line between quite and noisy \\
\hline $\mathbf{6 0}-\mathbf{7 0}$ & Fairly noisy \\
\hline Over 70 & Very noisy \\
\hline
\end{tabular}

Source - (Eysenck,1975) 
Table.3 Analysis of noise level at different workplaces of selected oil industries

\begin{tabular}{|c|c|c|c|c|c|c|c|c|c|}
\hline \multirow[t]{2}{*}{ Industry } & \multicolumn{3}{|c|}{ Work place 1 (Seed feeding) } & \multicolumn{3}{|c|}{ Work place 2 (Seeds Crushing ) } & \multicolumn{3}{|c|}{ Work place 3 (Oil expelling) } \\
\hline & $\begin{array}{l}\text { Noise } \\
\text { level }\end{array}$ & $\begin{array}{c}\text { Pollutio } \\
\text { n } \\
(\%)\end{array}$ & $\begin{array}{c}\text { General } \\
\text { subjective } \\
\text { judgment }\end{array}$ & Noise level & $\begin{array}{c}\text { Pollution } \\
(\%)\end{array}$ & $\begin{array}{c}\text { General } \\
\text { subjective } \\
\text { judgment }\end{array}$ & Noise level & $\begin{array}{c}\text { Pollutio } \\
\text { n (\%) }\end{array}$ & $\begin{array}{c}\text { General } \\
\text { subjective } \\
\text { judgment }\end{array}$ \\
\hline 1 & $77.2 \pm 0.46$ & 2.84 & $\mathrm{VN}$ & $83.32 \pm 0.87$ & 8.78 & VN & $79 \pm 0.54$ & 5.06 & VN \\
\hline 2 & $77.8 \pm 1.07$ & 3.59 & VN & $82.6 \pm 1.12$ & 9.2 & VN & $78.5 \pm 1.26$ & 4.45 & VN \\
\hline 3 & $76 \pm 1.60$ & 1.31 & VN & $84 \pm 1.22$ & 10.71 & VN & $77.6 \pm 1.40$ & 3.35 & VN \\
\hline 4 & $79.4 \pm 1.16$ & 5.54 & VN & $83.2 \pm 0.97$ & 9.85 & VN & $80.8 \pm 1.32$ & 7.17 & VN \\
\hline 5 & $78.8 \pm 1.11$ & 4.82 & VN & $84.4 \pm 1.12$ & 11.13 & VN & $73.2 \pm 2.18$ & -2.73 & VN \\
\hline 6 & $78.8 \pm 1.11$ & 4.82 & VN & $82.6 \pm 1.12$ & 9.2 & VN & $75.6 \pm 2.58$ & 0.79 & VN \\
\hline 7 & $79 \pm 1.22$ & 5.06 & VN & $83.6 \pm 0.98$ & 10.28 & VN & $76 \pm 1.98$ & 1.31 & VN \\
\hline 8 & $79.6 \pm 0.51$ & 5.77 & VN & $84.8 \pm 0.37$ & 11.55 & VN & $79.6 \pm 0.75$ & 5.77 & VN \\
\hline 9 & $79.8 \pm 1.74$ & 6.01 & VN & $82.8 \pm 1.71$ & 9.42 & VN & $80.4 \pm 1.47$ & 6.71 & VN \\
\hline 10 & $79.2 \pm 1.24$ & 5.3 & VN & $83 \pm 0.95$ & 9.63 & VN & $76.6 \pm 2.46$ & 2.08 & VN \\
\hline 11 & $\begin{array}{c}78.16 \pm 0.4 \\
3\end{array}$ & 4.04 & $\mathrm{VN}$ & $82 \pm 0.70$ & 8.53 & $\mathrm{VN}$ & $79 \pm 0.41$ & 5.06 & VN \\
\hline 12 & $80 \pm 1.05$ & 6.25 & VN & $82.92 \pm 0.62$ & 9.55 & VN & $76.2 \pm 2.15$ & 1.57 & VN \\
\hline 13 & $\begin{array}{c}78.26 \pm 0.4 \\
9\end{array}$ & 4.16 & $\mathrm{VN}$ & $83.2 \pm 0.43$ & 9.85 & $\mathrm{VN}$ & $79.24 \pm 0.79$ & 5.35 & VN \\
\hline 14 & $77.4 \pm 0.82$ & 3.1 & VN & $83.3 \pm 0.77$ & 9.96 & VN & $76.2 \pm 0.58$ & 1.57 & VN \\
\hline 15 & $\begin{array}{c}77.46 \pm 0.8 \\
6\end{array}$ & 3.17 & $\mathrm{VN}$ & $82.1 \pm 0.64$ & 8.64 & $\mathrm{VN}$ & $78.5 \pm 1.05$ & 4.45 & VN \\
\hline 16 & $\begin{array}{c}77.58 \pm 0.6 \\
6\end{array}$ & 3.32 & $\mathrm{VN}$ & $82.4 \pm 0.68$ & 8.98 & $\mathrm{VN}$ & $79.1 \pm 0.45$ & 5.18 & VN \\
\hline 17 & $78.5 \pm 0.89$ & 4.45 & $\mathrm{VN}$ & $82 \pm 0.89$ & 8.53 & VN & $79.5 \pm 0.38$ & 5.66 & VN \\
\hline 18 & $82.4 \pm 0.51$ & 8.98 & VN & $84.2 \pm 0.66$ & 10.92 & VN & $81.8 \pm 0.49$ & 8.31 & VN \\
\hline 19 & $78.2 \pm 0.37$ & 4.09 & VN & $81.4 \pm 0.75$ & 7.86 & VN & $80.6 \pm 0.92$ & 6.94 & VN \\
\hline 20 & $78.6 \pm 0.51$ & 4.58 & VN & $82.2 \pm 0.80$ & 8.75 & VN & $80.2 \pm 0.37$ & 6.48 & VN \\
\hline 21 & $78.9 \pm 0.33$ & 4.94 & VN & $83.26 \pm 1.12$ & 9.92 & VN & $80.4 \pm 0.38$ & 6.71 & VN \\
\hline 22 & $77.7 \pm 0.53$ & 3.47 & VN & $83.2 \pm 1.34$ & 9.85 & VN & $75.78 \pm 1.95$ & 1.02 & VN \\
\hline 23 & $\begin{array}{c}78.86 \pm 0.6 \\
1\end{array}$ & 4.89 & $\mathrm{VN}$ & $83.5 \pm 0.80$ & 10.17 & $\mathrm{VN}$ & $78.96 \pm 0.42$ & 5.01 & VN \\
\hline 24 & $78.8 \pm 0.25$ & 4.82 & VN & $84.4 \pm 0.81$ & 11.13 & VN & $78.74 \pm 0.16$ & 4.74 & VN \\
\hline 25 & $79.2 \pm 0.58$ & 5.3 & VN & $81.48 \pm 0.71$ & 7.95 & VN & $78.6 \pm 0.92$ & 4.58 & VN \\
\hline 26 & $77.2 \pm 0.58$ & 2.84 & VN & $81.66 \pm 1.02$ & 7.47 & VN & $78.16 \pm 0.54$ & 4.04 & VN \\
\hline 27 & $\begin{array}{c}78.68 \pm 0.3 \\
7\end{array}$ & 4.67 & VN & $82.6 \pm 1.24$ & 9.2 & VN & $79.88 \pm 0.30$ & 6.1 & VN \\
\hline 28 & $\begin{array}{c}79.42 \pm 0.4 \\
3\end{array}$ & 5.56 & VN & $83.7 \pm 1.04$ & 10.39 & $\mathrm{VN}$ & $80.74 \pm 0.45$ & 7.1 & VN \\
\hline 29 & $\begin{array}{c}78.72 \pm 0.4 \\
8\end{array}$ & 4.72 & $\mathrm{VN}$ & $80.3 \pm 0.30$ & 6.6 & VN & $78.92 \pm 0.78$ & 4.96 & VN \\
\hline 30 & $77.2 \pm 0.73$ & 2.84 & VN & $83.3 \pm 0.99$ & 9.96 & VN & $79.68 \pm 0.43$ & 5.87 & VN \\
\hline $\begin{array}{l}\text { Mean } \pm S \\
\text { Pollution } \\
\text { 'F' Value } \\
\text { CD }=0.51\end{array}$ & $\begin{array}{l}=78.54 \pm \\
=4.50 \\
182.858 * * \\
\quad \text { SE }=\end{array}$ & & & $\begin{array}{c}82.89 \pm \\
9.51\end{array}$ & & & $\begin{array}{c}78.57 \pm \\
4.54\end{array}$ & & \\
\hline
\end{tabular}

VN: Very noisy, ${ }^{* *}$ - Significant at $1 \%$ level 
Table.4 Comparison between inside and outside noise levels at different time intervals in selected oil industries

\begin{tabular}{|c|c|c|c|}
\hline \multirow{2}{*}{ Time intervals } & \multicolumn{2}{|c|}{$\begin{array}{c}\text { Noise Level } \\
\text { Mean } \pm \text { SD }\end{array}$} & \multirow{2}{*}{ 'Z' Value } \\
\cline { 2 - 3 } & $\begin{array}{c}\text { Inside Average Noise } \\
\text { level }\end{array}$ & $\begin{array}{c}\text { Outside Average Noise } \\
\text { level }\end{array}$ & \multirow{2}{*}{} \\
\hline $\mathbf{9 . 0 0}$ AM & $82.01 \pm 1.83$ & $76.88 \pm 2.09$ & $10.06^{* *}$ \\
\hline $\mathbf{1 . 0 0}$ PM & $83.84 \pm 1.56$ & $80.15 \pm 1.86$ & $8.2^{* *}$ \\
\hline $\mathbf{5 . 0 0}$ PM & $83.84 \pm 1.95$ & $78.68 \pm 2.61$ & $8.75^{* *}$ \\
\hline $\mathbf{9 . 0 0}$ PM & $75.49 \pm 3.98$ & $70.08 \pm 2.78$ & $6.07^{* *}$ \\
\hline
\end{tabular}

**-Significant at $1 \%$ level

Table.5 An average inside and outside percent noise pollution level at selected oil industries of different cities

\begin{tabular}{|c|c|c|c|c|c|}
\hline \multirow{2}{*}{ Sr. no. } & City & \multicolumn{2}{|c|}{ Inside Noise Pollution (\%) } & \multicolumn{2}{|c|}{$\begin{array}{c}\text { Outside noise Pollution } \\
(\%)\end{array}$} \\
\cline { 3 - 6 } & & Range & Average & Range & Average \\
\hline $\mathbf{1}$ & Parbhani (N=9) & $5.69-11.8$ & 8.95 & $-0.77-5.50$ & 1.54 \\
\hline $\mathbf{2}$ & Hingoli $(\mathrm{N}=6)$ & $7.6-8.93$ & 8.37 & $-0.26-2.61$ & 1.52 \\
\hline $\mathbf{3}$ & Aurangabad (N=3) & $7.4-9.22$ & 8.36 & $1.89-3.74$ & 2.61 \\
\hline $\mathbf{4}$ & Jalna $(\mathrm{N}=7)$ & $7.26-9.2$ & 8.29 & $0.05-5.53$ & 2.43 \\
\hline $\mathbf{5}$ & Nanded $(\mathrm{N}=5)$ & $5.97-8.69$ & 7.33 & $0.28-2.22$ & 1.43 \\
\hline
\end{tabular}

The General subjective judgments regarding certain intensives measured in dB

The general subjective judgments (perceived noise level) of the loudness of sound regarding certain intensives measured in $\mathrm{dB}$ considered in this study were as follows Findings

Data regarding analysis of noise level at different workplaces of oil industry is denoted in table 1. It is clear from the table that noise level in the work place-1(seed feeding area) varies from $76 \mathrm{~dB}-82 \mathrm{~dB}$ and percent noise pollution in the workplace-1 (seed feeding area) varies from 1.31-8.98 per cent. According to the general subjective judgment scale (Eysenck, 1975), workplace-1(seed feeding area) was judged as very noisy place.
In the workplace- 2 (seed crushing area) noise level varies from $80.3 \mathrm{~dB}-84.3 \mathrm{~dB}$, whereas percent noise pollution in workplace-2 (seed crushing area) varies from $6.6-11.55$ per cent judged as very noisy place. Regarding workplace-3 (oil expelling area) it was noticed that one oil industry had noise level below the acceptable limit i.e. $73.2 \mathrm{~dB}$, so that having pollution percent -2.73 , whereas the noise level of remaining 29 industries in workplace 3(oil expelling area) varies from $75.6 \mathrm{~dB}$ $81.8 \mathrm{~dB}$. With pollution percent variation from $0.79-8.31$ per cent judged as very noisy place.

Further it was also noticed that average noise level of the industries at workplace-1, workplace-2 and workplace-3 was 78.54, 82.89 and 78.57 respectively and average percent pollution of workplace-1, workplace-2 
and workplace-3 was 4.50 per cent, 9.51 per cent and 4.54 per cent respectively.

Calculated ' $\mathrm{F}$ ' values of analysis of variance result showed that statistically there was a highly significant relation between noise levels in all the three workplaces of oil industries. Conclusively it can be stated that noise level in work place-2 was higher than other two workplaces -1 and 3. All the three workplaces judged as very noisy while pollution percent is also high.

Statistically there was highly significant relation between noise levels at all the three workplaces of oil industries and average noise level.

Comparison of inside and outside noise levels at different time intervals in selected oil industries was carried out and presented in table 2. Table indicates that the average inside noise level of oil industries at 9.00 AM was 82.01 dB, while noise level at 1.00 PM and 5.00 PM was equal i.e. $83.84 \mathrm{~dB}$ and at 9.00 PM $75.49 \mathrm{~dB}$.

With respect to outside noise level it was noticed that average outside noise level at 9.00 $\mathrm{AM}$ was $76.88 \mathrm{~dB}$ whereas at $1.00 \mathrm{PM}, 5.00$ $\mathrm{PM}$ and 9.00 PM noise levels recorded were $80.15 \mathrm{~dB}, 78.68 \mathrm{~dB}$ and $70.08 \mathrm{~dB}$ respectively. Computed ' $Z$ ' values showed highly significant difference between inside and outside noise levels at different time intervals which indicated that inside noise level was significantly higher than outside noise of selected oil industries at different time intervals of the day.

Table 3 and depicts an average inside and outside percent noise pollution level at selected oil industries in different cities. In case of inside noise level Parbhani city had highest $(8.95 \%)$ noise pollution with range $5.69-11.8$ per cent, followed by Hingoli city
$(8.37 \%)$ with range 7.6 - 8.93 per cent, Aurangabad city $(8.36 \%)$ ranged between 7.4 - 9.22 per cent and Jalna city (8.29) with range $7.26-9.2$ per cent. Least average percent noise pollution was observed at Nanded city $(7.33 \%)$ with range of $5.97-8.69$ per cent.

For the outdoor situation, highest average percent noise pollution $(2.61 \%)$ was found in Aurangabad city with range $1.89-3.74$ per cent followed by Jalna city $(2.43 \%)$ with range $0.05-5.53$ per cent, Parbhani city (1.54\%) ranged between $-0.77-5.50$ per cent and Hingoli city $(1.52 \%)$ with range $-0.26-2.61$ per cent. Less average percent noise pollution $(1.43 \%)$ was noticed in industries of Nanded city ranged between $0.28-2.22$ per cent as compared to other selected cities.

An average percent pollution in inside noise levels of the oil industries as against the recommended limits was higher in Parbhani city and of outside noise level it was higher in the oil industries at Aurangabad city.

Noise level in work place-2 (Seeds Crushing) was higher than other two workplaces-1(Seed feeding) and 2 (Oil expelling). All the three workplaces judged as very noisy while pollution percent is also high. Statistically there was highly significant relation between noise level at all the three workplaces of oil industries and average noise level.

An average percent pollution in inside noise levels of the oil industries as against the recommended limits was higher in Parbhani city and of outside noise level it was higher in the oil industries at Aurangabad city.

\section{References}

Central Pollution Control Board (2001). Noise pollution regulations in India. Parivesh Bhawan, East Arjun Nagar Delhi - 110 032, pp: 27. http://envfor.nic.in/cpcb 
Eysenck (1975). Working environment and it's effect on health, safty and productivity. (As quoted by Bhatnagar (1995). Background material of training course on Ergonomics. Post Graduate Department of Family Resource Management, S.N.D.T. Women's University, Bombay, pp:120).

Gongi, S.P.; J.W. Kaluli and C.L. Kanali (2016). Industrial Noise Pollution and its Health Effects on Workers in Nairobi City. International Journal of Engineering Research \& Technology (IJERT), Vol. 5(9) : 426-435. http://www.ijert.org

Tiwari, T. N. (1990). Health hazards of pop music and their management. In: A. Rais, (ed.) environmental Pollution and Health Problems, Ashish Publication. New Delhi. pp. 101-115.

\section{How to cite this article:}

Jayshree Rodge and Bhagyashree Sangale. 2021. Noise Level at Different Workplaces of Selected Oil Industries. Int.J.Curr.Microbiol.App.Sci. 10(07): 130-136.

doi: https://doi.org/10.20546/ijcmas.2021.1007.015 